\title{
Study of the Bond at the Zirconia / Feldspathic Ceramic Interface
}

\author{
Anne-Christelle Makhlouf ${ }^{1}$, Elie Nasr ${ }^{2 *}$ \\ ${ }^{1}$ Masters in Aesthetic \& Prosthetic Dentistry, Resident in the Department of Fixed Prosthesis and Occlusodontics of the Faculty of Dentistry at Saint \\ Joseph University, Beirut, Lebanon \\ ${ }^{2}$ Responsible for teaching at the Department of Fixed Prosthesis and Occlusodontics of the Faculty of Dentistry at Saint Joseph University, Beirut, \\ Lebanon
}

${ }^{\star}$ Correspondence author: Elie Nasr, Department of Fixed Prosthesis and Occlusodontics of the Faculty of Dentistry at Saint Joseph University, Beirut, Lebanon; E-mail: elie.nasr1@usj.edu.lb

Received: July 05, 2018; Accepted: August 03, 2018; Published: August 17, 2018;

\begin{abstract}
The growing aesthetic demands of patients have led to the development of different types of all-ceramic crowns. Y-TZP zirconia-based restorations with feldspathic ceramic guarantee more satisfaction in terms of mimicry and biocompatibility than the metal-ceramic crowns. However, the bond at the zirconia and veneered porcelain interface seems to be the weakest link in this type of restoration. Indeed, numerous cases of interfacial decohesion of the cosmetic ceramic have been reported. For this purpose, numerous scientific studies have been carried out to further explore and accurately describe the characteristics of the interface at these two ceramics in order to strengthen the bond of bilayered ceramics.
\end{abstract}

Keywords: Y-TZP Zirconia, Veneered Porcelain, Interface, Bond Strength, Decohesion

\section{Introduction}

The objective of fixed dental prosthesis has always been to restore the morphology and occlusal function of the teeth to give the patient satisfactory chewing by integrating the prosthetic element seamlessly.

The metal-ceramic crown meets these mechanical and aesthetic requirements is still considered to be the gold standard in fixed prosthesis. However, the importance of aesthetics is growing rapidly in today's society, and the metal-ceramic system, although clinically reliable in the long term, gives less satisfaction in terms of mimicry and biocompatibility. "The restoration of the natural appearance of a smile cannot be designed without the use of all-ceramic systems." (John MacLean, 1975)

Nowadays, the development of new ceramic which is more resistant and offers excellent light transmission has made it possible to extend to all the clinical situations the application of all-ceramic crown to all clinical situations. The alliance of professional skills and innovations in biomaterials brought Y-TZP zirconia-based infrastructures (Yttrium Tetragonal Zirconia Polycrystal) forward in the early 1990s. Given its mechanical properties, Y-TZP zirconia can now expand the indications of this all-ceramic system to multi-prosthetic processes. In response to today's growing demands of biocompatibility and aesthetics, Y-TZP zirconia infrastructures appear as a prosthetic solution that should not be overlooked.

However, the problem durability of ceramo-ceramic restorations arises. Indeed, many cases of cosmetic ceramics fracture along the interface with the Y-TZP zirconia-based infrastructure have been reported [1]. This clinical observation was the subject of many scientific studies aiming to explore the existing link between the Y-TZP zirconia-based infrastructure and the veneered ceramic.

The aim of this article is the synthesis of scientific data acquired through experimental research, in regards to both the origin and propagation mode of the various cracks in the ceramic, as well as the strength of the bond at the zirconia / feldspathic ceramic interface, and the factors influencing it.

\section{Characteristics of the Interface}

The long term success of the ceramo-ceramic crowns consisting of veneering ceramic to zirconia is a critical issue. Indeed, the zirconiabased restorations constitute a high percentage of cosmetic ceramics fracture. As a matter of fact, the rate of fracture in vivo of laminating ceramics is $15 \%$ after 24 months, $25 \%$ after 31 months, whereas it is only $2.9 \%$ after 36 months for metal-ceramic restorations [2]. The location of the interface as an original defect was reported, suggesting that the link between the veneering ceramic and the zirconia-based infrastructure is the weakest link in this type of restoration [3].

\subsection{The Different Modes of Interaction Occurring between the Structural Ceramic and the Cosmetic Ceramic}

Existing studies have focused on some critical clinical perspective issues regarding the quality of the connection at the level of the interface of zirconia and the veneered ceramic.

It was shown that the combination of structural analysis techniques such as Raman confocal microscopy (Figure1) and the 
recently introduced FIB / SEM (Figure 2, 3) analysis in microscopy ensured a better understanding of the relationship between the two similar but physically incomparable ceramic materials. Indeed, feldspathic ceramic has a biphasic structure: vitreous and crystalline, while zirconia is a polycrystalline ceramic.

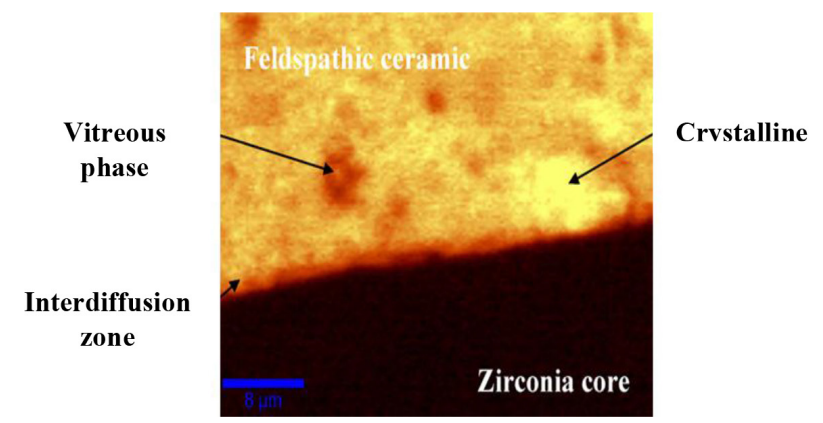

Figure 1. Confocal Raman microscopic analysis of the zirconia / feldspathic ceramic interface. (Durand et al, 2012)

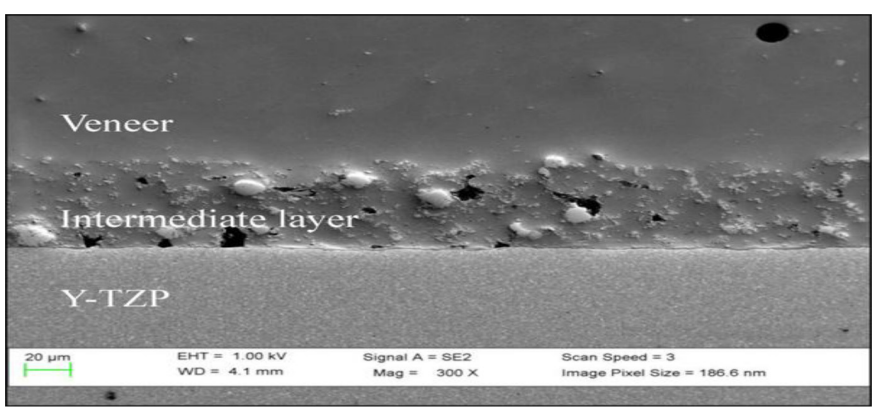

Figure 2. Microstructural analysis FIB / SEM of the zirconia and the veneered ceramic interface. (Mainjot et al, 2013)

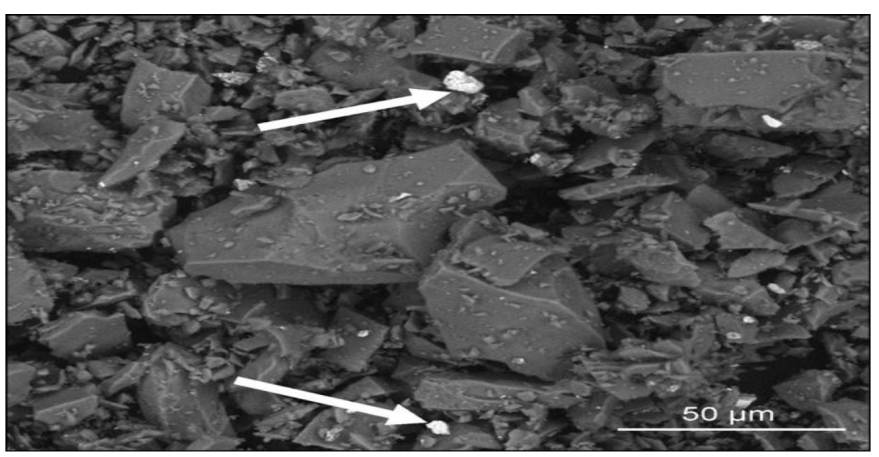

Figure 3. The FIB / SEM analysis of the interdiffusion zone, shows the presence of zirconia crystals (white arrows) within the feldspathic ceramic. (Mainjot et al, 2013)

Microscopic observations revealed three different structural layers. However, the presence of an intermediate layer of $50 \mu \mathrm{m}$ thickness in the cosmetic ceramic in contact with zirconia, has defined a process of interdiffusion (i.e. mutual diffusion). Thus, this transition layer is characterized by the presence of zirconia particles (certified by the EDS), up to $20 \mu \mathrm{m}$ in size in the glass matrix.

\subsubsection{Chemical Interaction}

Existing literature gives little evidence as to the presence of a chemical bond between the zirconia-based infrastructure and veneered feldspathic ceramic. No scientific evidence of a chemical bond between the two materials has been put forward.

The adhesion between the structural and cosmetic ceramic depends on the basic material. In the case of a glass-infiltrated ceramic infrastructure (e.g. InCeram Spinell, InCeram Alumina, InCeram Zirconia), a chemical bond is established by diffusion of the glass into the cosmetic ceramic during sintering.

Polycrystalline ceramics have low vitreous mass (1\%), which calls into question the presence of a chemical bond between zirconia and the veneered ceramic.

\subsubsection{Mechanical Interaction}

The absence of tangible evidence indicating the presence of a chemical bond between the zirconia-based infrastructure and veneered feldspathic ceramic, suggests that it is the mechanical link that plays the major role in the integration of the two materials together.

The mechanical phenomena are very well documented and widely accepted by the scientific community. Accordingly, they can be broken down into two principles.

\subsubsection{The Compressive Stresses}

The development of compressive stresses by the cosmetic ceramic on the infrastructure is mechanically favorable, since direction of these stresses opposes the propagation of cracks from inter-facial defects and compensates for the tension stresses at the surface of the zirconia. These compressive stresses arise from the difference in the coefficients of thermal expansion between two ceramics.

The coefficient of thermal expansion is a characteristic of the dimensional changes of a sample of material that depends on the variation in temperature. It is given by the following relation: $\Delta \mathrm{L}=$ $\alpha \cdot \mathrm{L}_{0} \cdot \Delta \mathrm{T}$

With: $-\Delta \mathrm{L}$ : Length variation of the sample $(\mathrm{m})$

- $\alpha$ : Coefficient of thermal expansion $\left(\mathrm{K}^{-1}\right.$ or $\left.{ }^{\circ} \mathrm{C}^{-1}\right)$

$-\mathrm{L}_{0}$ : Initial length of the sample $(\mathrm{m})$

$-\Delta \mathrm{T}$ : Temperature variation $\left(\mathrm{K}\right.$ or $\left.{ }^{\circ} \mathrm{C}\right)$

The higher the value of the coefficient of thermal expansion, the more the material will tend to expand during sintering, and shrink upon cooling. This explains the importance of having similar coefficients of thermal expansion between the structural ceramic and the cosmetic ceramic in order to avoid expansion cracks.

Ideally, the two coefficients of thermal expansion should be identical with a slightly lower coefficient of thermal expansion for the cosmetic ceramic compared to the structural ceramic, so as not to generate a crack in the veneered ceramic during its cooling. Indeed, the fragile cosmetic ceramic is mechanically more resistant when it is compressed compared to when it is in a state of tension. Mastering the thermal properties of different ceramics is essential to ensure a sustainable, durable restoration. In order to increase the bond strength between the zirconia framework and the veneered ceramic, the coefficient of thermal expansion of the cosmetic ceramic 
should be slightly less than the coefficient of thermal expansion of the infrastructure. Thus, the compressive stresses created reinforce the bond between the two ceramics.

\subsubsection{Micromechanical Retention}

It corresponds to the "entanglement rate" of the feldspathic ceramic in the infrastructure. This mechanical locking between the two materials is due to surface irregularities of the zirconia that are present prior to the veneering procedure.

This micromechanical adhesion will be dependent on the surface roughness of the infrastructure due to the milling, polishing, and sandblasting procedures, as well as the ability of the cosmetic ceramic to lodge in these rough edges (size grains, wettability).

The preparation of the surfaces of the infrastructure must provide sufficient roughness to increase the surface area in contact with the provided mass of the cosmetic ceramic. However, excessive roughness leads to deep grooves that reduce grip and weaken the bond strength.

\subsection{Experimental Values of the Bond Strength}

In order to study the bond strength at the zirconia and the veneered ceramic interface, Ozkurt et al. [2] selected four types of zirconia-based ceramics: Zirkonzahn, Cercon, Lava, and DC-Zircon. For each zirconia system, 30 disk samples were veneered with IPS e.max Ceram, Vita VM9, and a coating ceramic recommended by the manufacturer. (Tabel 1) A SBS (Shear Bond Strength) test was performed, and a fracture surface analysis was also conducted to determine failure modes, categorized as follows:

- Cohesive fracture : Rupture within the cosmetic ceramic.

- Adhesive fracture : Rupture at the interface.

- Combined fracture : Combination of the two aforementioned fracture modes.

Table 1. Average bond strength (MPa) and fracture mode (\%) for different combinations of zirconia-based and veneered ceramics. (Ozkurt et al, 2010)

\begin{tabular}{|c|c|c|c|}
\hline \multirow{2}{*}{$\begin{array}{c}\text { Zirconia } \\
\text { Infrastructure } \\
\text { Ceramic }\end{array}$} & Feldspathic & Bond Strength & Failure Mode \\
\hline & Cosmetic Ceramic & (MPa) & $(\%)$ \\
\hline \multirow{5}{*}{ Zirkonzahn } & \multirow{2}{*}{ Ice Keramik ${ }^{\circledR}$} & \multirow{2}{*}{24,46} & $50 \%$ adhesive \\
\hline & & & $50 \%$ combined \\
\hline & \multirow{2}{*}{ IPS e.max Ceram ${ }^{\circledR}$} & \multirow{2}{*}{26,04} & $50 \%$ adhesive \\
\hline & & & $50 \%$ combined \\
\hline & Vita VM9® & 26,52 & $100 \%$ combined \\
\hline \multirow{5}{*}{ Cercon } & \multirow{2}{*}{ Cercon Ceram ${ }^{\circledR}$} & \multirow{2}{*}{20,19} & $80 \%$ adhesive \\
\hline & & & $20 \%$ combined \\
\hline & \multirow{2}{*}{ IPS e.max Ceram ${ }^{\circledR}$} & \multirow{2}{*}{24,17} & $50 \%$ adhesive \\
\hline & & & $50 \%$ combined \\
\hline & Vita VM9® & 21,67 & $100 \%$ combined \\
\hline
\end{tabular}

\begin{tabular}{|c|c|c|c|}
\hline \multirow{2}{*}{$\begin{array}{c}\text { Zirconia } \\
\text { Infrastructure } \\
\text { Ceramic }\end{array}$} & Feldspathic & Bond Strength & Failure Mode \\
\hline & Cosmetic Ceramic & (MPa) & $(\%)$ \\
\hline \multirow{6}{*}{ Lava } & \multirow{2}{*}{ Lava Ceram ${ }^{\circledR}$} & \multirow{2}{*}{27,11} & $30 \%$ adhesive \\
\hline & & & $70 \%$ combined \\
\hline & \multirow{2}{*}{ IPS e.max Ceram ${ }^{\circledR}$} & \multirow{2}{*}{23,05} & $60 \%$ adhesive \\
\hline & & & $40 \%$ combined \\
\hline & \multirow{2}{*}{ Vita VM9® } & \multirow{2}{*}{18,66} & $50 \%$ adhesive \\
\hline & & & $50 \%$ combined \\
\hline \multirow{5}{*}{ DC-Zirkon } & \multirow{2}{*}{$\operatorname{Triceram}{ }^{\circledR}$} & \multirow{2}{*}{40,49} & $50 \%$ adhesive \\
\hline & & & $50 \%$ combined \\
\hline & \multirow{2}{*}{ IPS e.max Ceram ${ }^{\circledR}$} & \multirow{2}{*}{21,38} & $50 \%$ adhesive \\
\hline & & & $50 \%$ combined \\
\hline & Vita VM9® & 31,51 & $100 \%$ combined \\
\hline
\end{tabular}

\section{The Fracture}

The use of innovative materials, such as Y-TZP zirconia for ceramo-ceramic reconstructions, constitutes a breakthrough in the field of prosthetics. Its harmonious color and biological integration with the surrounding tissue perfectly match the current trends in aesthetics and biocompatibility.

However, the long term success of this type of restoration is still a major concern. Different fracture lines can be observed in these ceramo-ceramic crowns that break abruptly without prior plastic deformation. Moreover, the fracture occurs by propagation of a crack from an initial defect.

In this sense, various clinical studies were conducted to understand the possible failure mechanisms. In fact, the study of the origin and path of the fracture line is of great importance to determine the factors allowing or limiting the propagation of the crack along the zirconia and veneered ceramic interface.

\subsection{Origin of the Fracture}

Descriptive fractography is an effective imaging tool applied in dentistry to clinical failure analyses of ceramic restorations [4].

The analysis of the fractured surface at the level of defective ceramic crowns contributes to determine the direction of propagation of the crack, and trace the origin of the fracture [5].

\subsubsection{Occlusal}

One of the emerging causes of fracture in all-ceramic dental restorations is the generation of micro-cracks due to occlusal contacts and wear. This occlusal load falls under the bi-axial type; during a masticatory cycle the compression is always followed by a lateral sliding movement (Figure 4). These forces trigger a series of conical cracks in the cosmetic ceramic [6]. According to a study by Aboushelib et al. [7] the majority of porcelain zirconia single unit restorations fracture by initiation and propagation of conical cracks from the occlusal surface to the interface. 


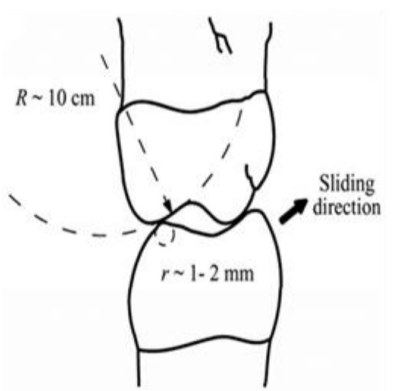

(a) Occlusion

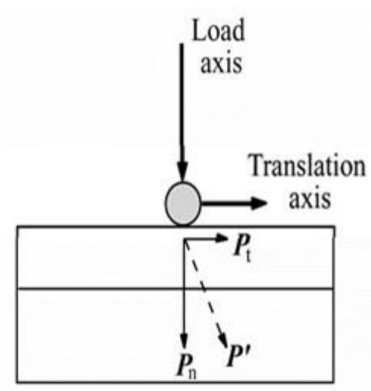

(b) Sliding sphere
Figure 4. Schematic representation of the forces involved during occlusal contact in a masticatory cycle. (Kim et al, 2007)

\subsubsection{Interface}

The fracture can also arise at the level of the zirconia and ceramic lamination interface. This type of failure is related to the low adhesive strength between the two ceramics used as well as the presence of localized tensile stresses at the interface level. These constraints which have a significant effect on the weakening of the bond are due to the incompatibility of the coefficients of thermal expansion between the two materials.

Aboushelib et al. [7] analyzed clinically fractured zirconia layered ceramics restorations; out of 19 examined unit crowns, 6 exhibited an interfacial decohesion (Figure 5).

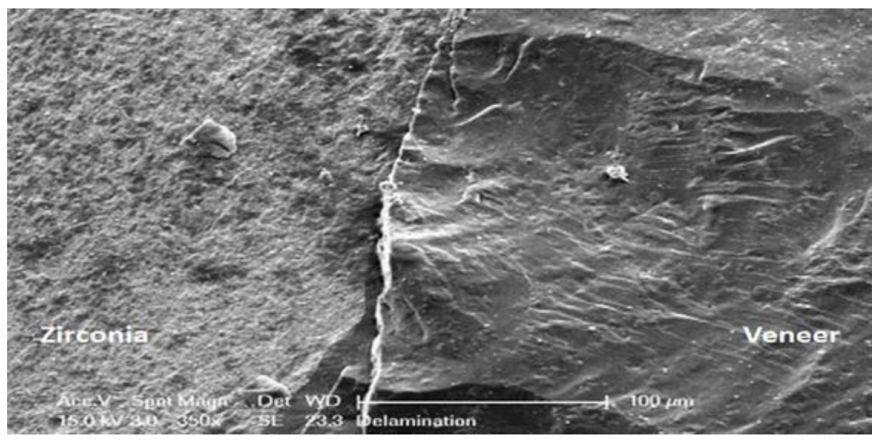

Figure 5. The SEM analysis of the zirconia and the veneered ceramic interface shows an interfacial decohesion. (Aboushelib et al, 2009)

\subsubsection{Bridge Connections}

Generally, bridge connections are weak spots and favor the concentration of constraints. Indeed, the connections are subject to constraints of tension and bending.

According to a study from Toskanak et al. [4], in the case of an Y-TZP zirconia-based infrastructure of a three-unit bridge veneered with a feldspathic ceramic, the fracture takes place in four of the five samples at the connection level, more specifically on the gingival side (Figure 6).

\subsection{The Crack Propagation}

A crack originates at a point of major stress concentration. It spreads when it receives the energy necessary for its elongation. However, the propagation of the crack is mainly dependent on the composition of the ceramic, the shape, the size, and the orientation of the grain, but is also affected by the rate of residual stresses in the material [8].
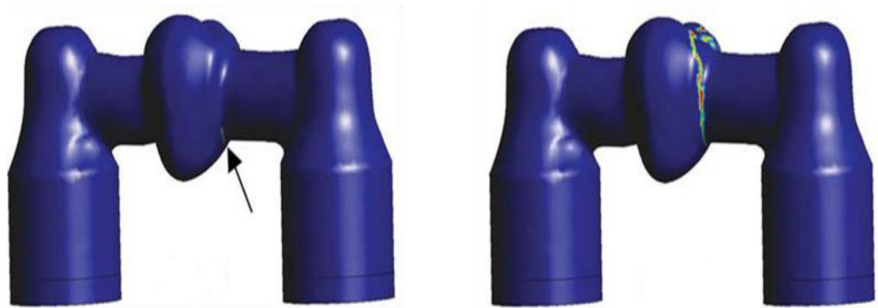

Figure 6. The 3D numerical modeling is used to simulate the fracture initiation sites of an Y-TZP bridge. (Kou et al, 2011)

\subsubsection{The Hertzian Cone Cracks}

These cracks progress very quickly, at relatively low charges $(<100 \mathrm{~N})$, but generally do not broadcast very far inside the sample. They initially develop in the form of a superficial ring then spread unstably and stop taking the form of a cone. They are able to maintain stability without causing a fracture.

\subsubsection{The Internal Cone Cracks}

These cracks appear only after repetitive loads. They spread quickly and deeply in the direction of the zirconia / feldspathic ceramic interface, which can cause the mass fracture of the restoration.

\subsubsection{The Radial Cracks}

These cracks are formed at high and continuous loads (200 to $600 \mathrm{~N})$. They originate from a pre-existing defect at the inner surface of the cosmetic ceramic, when the tensile stress exceeds the flexural strength of the material.

This type of crack has been identified as the main mode of failure in all-ceramic crowns [9].

\section{The Required Criteria to Achieve a Better Cera- mo-Ceramic Connection}

Thanks to various scientific researches, light was shed on the multiple variables affecting the ceramo-ceramic bond strength. In fact, understanding the characteristics of the interface between zirconia and the veneered ceramic made it possible to adjust the various parameters, thus leading to the design of a sustainable restoration.

\subsection{Surface Treatment}

In what follows, we will describe the procedures commonly used in the surface treatment of zirconia before the veneering procedure.

\subsubsection{Sandblasting}

Nowadays, it is commonly accepted that sandblasting with alumina oxide at $50 \mu \mathrm{m}$ with a pressure of 2 bar causes a significant increase in the mechanical properties of zirconia by allowing the formation of a compressive layer on the surface.

The impact of sand on the surface of zirconia induces residual stresses that promote the conversion of tetragonal particles into monoclinic particles. This phase transformation is accompanied by a volume increase of 3 to $5 \%$ of the monoclinic crystals inducing the formation of a compressive surface layer. 
However, the surface defects introduced by sandblasting (Figure 7) must be less deep than the thickness of the compressive layer to obtain an increase in the fracture resistance.
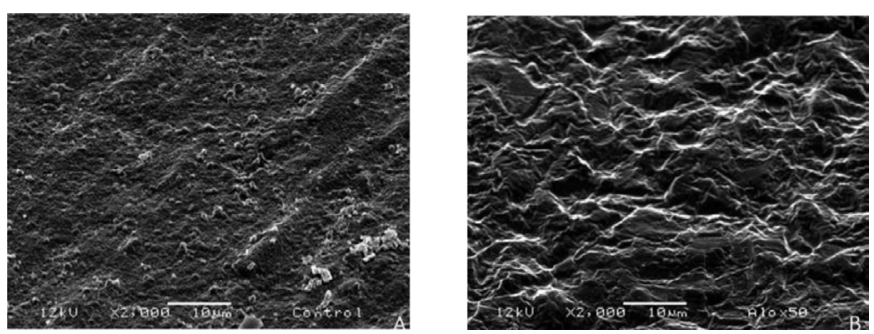

Figure 7. Observation under an electron microscope, the surface of the zirconia before (A) and after (B) sandblastinging with alumina oxide at $50 \mu \mathrm{m}$. (Hjerppe et al, 2016)

Fischer et al. [10] studied the effect of sandblasting of zirconia on bond strength with feldspathic ceramic. By observing the fracture mode of the specimens, they deduced that the crack propagates towards the interface, but against the compressive layer, the latter changes direction and diffuses parallel to the interface in the thickness of the cosmetic ceramics.

The sandblasting technique, which is widely used in the dental prosthesis laboratory, proves to be advantageous in terms of mechanical strength resistance of the zirconia-based infrastructure.

\subsubsection{Application of a Liner}

The "liner" corresponds to a specific layer composed of feldspathic ceramic enriched with selenium (Se), used initially to mask the color of the zirconia, which is too white, by generating a colored background [11].

However, its application on zirconia infrastructure before veneering is not recommended [12] since its use decreases the ceramoceramic adhesion force $[13,14]$.

\subsection{The Cooling Speed}

Zirconia is a bad thermal conductor, and this is an important factor to take into consideration to correct the sintering mechanisms of the cosmetic ceramic.

Tan et al. [3] have shown that the mechanical properties of a veneered zirconia framework restoration are doubled by the use of slow heating and cooling regimes.

However, it is the cooling speed that greatly influences the ceramo-ceramic bond strength. Indeed, during cooling after sintering, the surface of the cosmetic ceramic cools quickly while the cosmetic interface progressively cools. This "gradient solidification" entails the incorporation of numerous residual thermal stresses between the infrastructure and veneered ceramic.

According to Rues et al. and Guazzato et al. $[15,16]$ fast cooling results in compressive residual stresses while slow cooling results in the formation of extensive residual stresses.

The presence of compressive stresses increases the bond strength of zirconia and veneered ceramic, but also promotes the probability of chipping of the cosmetic ceramic. On the other hand, extensive stresses decrease the ceramo-ceramic bond strength, but prevent cosmetic chips [15].

Therefore, the residual thermal stresses must be controlled in order to strengthen the ceramo-ceramic adhesion without risking to weaken the veneered ceramic.

Currently, the slow heating and cooling regimes are widely adopted by dental technicians.

\section{Conclusion}

The growing demand for aesthetic restorations that replicate natural looks and the increasing concerns about the metal restorations have been the driving force behind the development of new materials and techniques in the field of the fixed dental prosthesis.

Nowadays, all-ceramic crowns are gaining well-deserved ground. Indeed, the Y-TZP zirconia-based infrastructure veneered with a feldspathic ceramic meets the rational requirements of the patient in search for aesthetics, biocompatibility and function.

However, clinical studies report an increased incidence and severity of fractures in this type of restoration. The fractographic analysis makes it possible to determine the failure modes, the origins of rupture and the propagation of cracks at the level of these ceramoceramic crowns.

The various types of failures found such as cohesive fracture or "chipping" at the level of cosmetic ceramics and interfacial decohesion are complex and depend on the internal factors (compositions, properties) and external factors (masticatory forces applied) to the materials.

The bond at the zirconia and veneered ceramic interface has proven to be a real challenge. Below are the criteria that must be adapted to obtain a viable restoration, able to withstand intraoral conditions:

- Sandblasting with alumina oxide at $50 \mu \mathrm{m}$ with a pressure of 2 bar on the surface of the zirconia.

- Controlled cooling regimes during the different sintering phases.

- Similar coefficients of thermal expansion with a coefficient of expansion slightly lower for the ceramic overlay compared to that of the structural ceramic.

Thus, in order to overcome the problems of bilayer structures, monolithic crowns made from polychromatic zirconia, characterized by a fine and homogeneous structure, and shaped using CAD / CAM procedures have been placed on the market. The latter are promising in terms of aesthetics and mechanics. In the meantime, only clinical and in vitro studies will provide the data needed to the universal consent to their use in the near future.

\section{References}

1. Baldassarri M, Zhang Y, Thompson VP, Rekow ED, Stappert CFJ (2011) Reliability and failure modes of implant-supported zirconium-oxide fixed dental prostheses related to veneering techniques. J Dent 39: 489-498.

2. Ozkurt Z, Kazazoglu E, Unal A (2010) In vitro evaluation of shear bond strength of veneering ceramics to zirconia. Dent Mater J 29: 138-146. [crossref] 
3. Tan JP, Sederstrom D, Polansky JR, McLaren EA, White SN (2012) The use of slow heating and slow cooling regimens to strengthen porcelain fused to zirconia. $J$ Prosthet Dent 107: 163-169. [crossref]

4. Taskonak B, Yan J, Mecholsky JJ Jr, Sertgöz A, Koçak A (2008) Fractographic analyses of zirconia-based fixed partial dentures. Dent Mater 24: 1077-1082. [crossref]

5. Pang Z, Chughtai A, Sailer I, Zhang Y (2015) A fractographic study of clinically retrieved zirconia-ceramic and metal-ceramic fixed dental prostheses. Dent Mater 31: 1198-1206.

6. Kim JW, Kim JH, Thompson VP, Zhang Y (2007) Sliding contact fatigue damage in layered ceramic structures. J Dent Res 86: 1046-1050. [crossref]

7. Aboushelib MN, Feilzer AJ, Kleverlaan CJ, (2009) Bridging the gap between clinical failure and laboratory fracture strength tests using a fractographic approach. Dent Mater 25: 383-391.

8. Etman MK (2009) Confocal examination of subsurface cracking in ceramic materials. J Prosthodont 18: 550-559. [crossref]

9. Lawn BR, Deng Y, Lloyd IK, Janal MN, Rekow ED, et al. (2002) Materials design of ceramic-based layer structures for crowns. J Dent Res 81: 433-438. [crossref]
10. Fischer J, Stawarczyk B, Hämmerle CH (2008) Flexural strength of veneering ceramics for zirconia. J Dent 36: 316-321. [crossref]

11. Fouquier R (2008) La zirconne comment je m'y accroche. Tech Dent 263: 7-17.

12. Alghazzawi TF, Janowski GM (2016) Effect of liner and porcelain application on zirconia surface structure and composition. Int J Oral Sci 8: 164-171. [crossref]

13. Ishibe M, Raigrodski AJ, Flinn BD, Chung KH, Spiekerman C, et al. (2011) Shear bond strengths of pressed and layered veneering ceramics to high-noble alloy and zirconia cores. J Prosthet Dent 106: 29-37. [crossref]

14. Wang G, Zhang S, Bian C, Kong H (2014) Interface toughness of a zirconia-veneer system and the effect of a liner application. J Prosthet Dent 112: 576-583. [crossref]

15. Rues S, Kröger E, Müller D, Schmitter M (2010) Effect of firing protocols on cohesive failure of all-ceramic crowns. J Dent 38: 987-994. [crossref]

16. Guazzato M, Walton TR, Franklin W, Davis G, Bohl C, et al. (2010) Influence of thickness and cooling rate on development of spontaneous cracks in porcelain/ zirconia structures. Aust Dent J 55: 306-310. [crossref]

\section{Citation:}

Anne-Christelle Makhlouf, Elie Nasr (2018) Study of the Bond at the Zirconia / Feldspathic Ceramic Interface. J Dent Maxillofacial Res Volume 1(1): 1-6. DOI: 10.31038/JDMR.1000102 